\title{
Las tramas judiciales del «delito de independencia» durante la crisis virreinal y monárquica, Río de la Plata, 1806/08-1810*
}

\author{
The Judicial Plots of the «Crime of Independence» \\ During the Viceregal and Monarchical Crisis, \\ Río de la Plata, 1806/08-1810
}

\author{
Irina Polastrelli \\ ORCID iD: http://orcid.org/0000-0003-0704-3508
}

Universidad Nacional de Rosario / CONICET

Este artículo muestra las alternativas planeadas para afrontar la crisis virreinal y monárquica en el Río de la Plata y los esfuerzos de las autoridades coloniales para condenarlas bajo la acusación común de «delito de independencia». A través del análisis de causas judiciales, se revelan los múltiples significados del concepto de independencia y su uso político durante la crítica coyuntura, así como también las disputas por el reparto del poder entre las autoridades involucradas.

Palabras clave: Independencia; Río de la Plata; Crisis Virreinal; Crisis de la Monarquía; Procesos Judiciales; Delitos Políticos.

This article shows the alternatives projected by certain actors in order to confront the viceregal and monarchical crisis in the Rio de la Plata and the efforts of the colonial authorities to condemn them under the common accusation of «crime of independence». The analyses of judicial cases demonstrates the multiple meanings of the concept of independence and its political use during the critical situation, as well as disputes for the distribution of power between the authorities involved.

KeYwords: Independence; Río de la Plata; Viceregal Crisis; Crisis of Monarchy; Trials; Political Crimes.

Copyright: (C) 2019 CSIC. Este es un artículo de acceso abierto distribuido bajo los términos de la licencia de uso y distribución Creative Commons Reconocimiento 4.0 Internacional (CC BY 4.0)

* Este trabajo ha sido financiado por dos becas doctorales del Consejo Nacional de Investigaciones Científicas y Técnicas (CONICET, PG Tipo I 09 y PG Tipo II 12). El argumento central del apartado «Los planes independentistas de Saturnino Rodríguez Peña y Diego Paroissien» ha sido desarrollado de manera exhaustiva en Polastrelli, 2016. Agradezco los comentarios de los doctores Marcela Ternavasio, Darío Barriera, Noemí Goldman y Gabriel Entin, así como también las valiosas sugerencias de los evaluadores de la revista. 


\section{Introducción}

La vacancia en el trono producida con las célebres abdicaciones de Bayona en mayo de 1808 sumió a la monarquía española en una crisis inédita. En el Río de la Plata, dicha crisis se superpuso a la situación de inestabilidad política e institucional heredada con la invasión y ocupación de la capital virreinal por las tropas británicas en 1806 y 1807, hecho que tuvo entre sus consecuencias la destitución del virrey Rafael de Sobremonte por medio de una Junta de Guerra. A nivel local, aunque la incertidumbre jurídica que siguió a 1806 no fue comparable en su naturaleza a la desencadenada por la vacatio regis poco tiempo después, sí se asemejó en dos aspectos: en primer lugar, se vinculó a la situación de provisionalidad vivida en esos meses; en segundo, a la emergencia de un margen de autonomía por parte de las autoridades coloniales respecto de la metrópoli. ${ }^{1}$

La crisis monárquica abrió una nueva etapa donde, al problema de la obediencia política que había dejado al descubierto la deposición del virrey, se sumó un problema de mayor dimensión: el de la soberanía. ${ }^{2}$ Los efectos que provocaron los sucesos peninsulares de 1808 en el Río de la Plata no derivaron de 1806 sino que dotaron a ese escenario de un nuevo desafío que se jugaba a escala imperial. La destitución del virrey en 1807, la Junta de Montevideo en 1808 y los movimientos juntistas en la capital y en el Alto Perú durante el año 1809 expusieron a las autoridades a una frágil situación, y evidenciaron que antes de 1810 el orden colonial —retomando una expresión de Tulio Halperin Donghi- adolecía de grietas cuya profundidad no es sencillo medir. ${ }^{3}$

La historiografía tradicional canonizó para el caso rioplatense una clásica cronología que iniciaba el proceso revolucionario en 1810. Historiadores como Bartolomé Mitre y Vicente Fidel López, seguidos por Ricardo Levene, entre muchos otros, caracterizaron a la Revolución como momento fundacional y punto de partida para mirar los años precedentes. De esos años, rescataban las invasiones inglesas como prefacio de la gesta revolucionaria, en tanto habían contribuido a moldear el espíritu independentista rioplatense, que mostraría todo su vigor luego de 1810 . De esta

1 Ternavasio, 2010a. Para una lectura de la coyuntura de 1808 en el Río de la Plata como la conjunción de situaciones de carácter local, regional e internacional, véase Ortelli y Barral, 2008. Sobre las invasiones inglesas de 1806 y 1807, véase Gallo, 1994.

2 Idem.

3 Halperin Donghi, 2005, 135-136. 
manera, las consecuencias de la reconquista y la defensa de Buenos Aires eran consideradas una manifestación de las «fuerzas endógenas» (en las que 1810 ya estaba inscripta), mientras que 1808 constituía un momento más, de carácter «exógeno», en la sucesión de acontecimientos que explicaban la Revolución. ${ }^{4}$ Esta cronología ha sido revisada en los últimos años, fundamentalmente a partir del diálogo con interpretaciones que prestan una mayor atención a los acontecimientos peninsulares. ${ }^{5}$ En esta línea se subraya también que el movimiento juntista peninsular y la formación de las primeras juntas americanas durante el «bienio trascendental» ${ }^{6}$ (explicadas por las historiografías nacionales de los países hispanoamericanos como intentos fracasados de independencia o antecedentes de las emancipaciones posteriores) se caracterizaron en realidad por una férrea fidelidad al monarca español y constituyeron una respuesta a la crisis peninsular, al temor que despertó la posibilidad de depender de Francia y, en los casos de Montevideo, La Paz y Charcas, a tensiones jurisdiccionales de larga data. ${ }^{7}$ La crisis monárquica de 1808 y el bienio que le siguió se reubicaron, por lo tanto, como una coyuntura crucial en el proceso que culminó con las independencias. Un proceso y una periodización que siguen siendo objeto de debate dentro de los diversos campos de la disciplina, pero que admiten el rol decisivo que tuvo la crisis en la disgregación de la monarquía hispánica y sus dominios. ${ }^{8}$

En el marco de estas discusiones, las causas judiciales estudiadas en este artículo iluminan algunos aspectos de la secuencia de la crisis en el virreinato del Río de la Plata. Los casos seleccionados exponen los dos momentos de inflexión antes mencionados - la grieta imperial de 1806 y la crisis monárquica de 1808 - y muestran las alternativas ensayadas (o al menos pensadas) para remediar la crítica coyuntura, así como también el cuestionamiento que esto supuso de parte de ciertos actores hacia las autoridades coloniales y, en definitiva, hacia el orden colonial, aunque no hacia la monarquía. Las causas abiertas contra Saturnino Rodríguez Peña y Diego Paroissien por sus proyectos «independentistas» para el Río de la Plata, el

4 Ternavasio, 2010a, 55.

5 La obra paradigmática al respecto es la de Guerra, 1992.

6 Tomamos la expresión de Chust, 2007b.

7 Sobre la relevancia del bienio 1808-1810 y la formación de juntas en el mundo hispánico durante dicha coyuntura remitimos a: Breña, 2010; Chust, 2007a; Buriano y Grafenstein, 2008; Peralta Ruiz, 2013.

8 Una revisión intensa de dichos debates se encuentra en Piqueras, 2008. Véase también: Palti, 2009. Ternavasio, $2010 \mathrm{~b}$. 
sumario instruido a Juan Martín de Pueyrredón por su actuación durante la crisis de 1808, y el procesamiento de quienes participaron en la asonada del $1 .^{\circ}$ de enero de 1809 contra el virrey Santiago de Liniers en Buenos Aires ilustran el esfuerzo denodado de las autoridades coloniales asentadas en la capital virreinal para reprimir y condenar dichas alternativas, que paulatinamente fueron criminalizadas bajo una acusación que englobaba a todas: la de promover planes de «independencia». ${ }^{9}$ La puesta en relación de los casos mencionados con la represión militar y judicial de las juntas de La Plata y La Paz permite asimismo ponderar las diversas valoraciones y los tratamientos disímiles recibidos por los episodios que conmocionaron al virreinato durante el período delimitado. ${ }^{10}$ Los procesos analizados dejan al desnudo los diferentes significados que el concepto de «independencia» adoptó en esos tormentosos momentos y cómo fue usado políticamente por los bandos en disputa. ${ }^{11}$

\section{Los planes «independentistas» de Saturnino Rodríguez Peña y Diego Paroissien}

Saturnino Rodríguez Peña era un porteño que entre 1806 y 1807 abrazó la alternativa de una «independencia» tutelada por Inglaterra a raíz de los contactos que estableció con William Carr Beresford, general inglés que cayó prisionero luego de fracasar su empresa de conquistar Buenos Aires en 1806. Fue denunciado por el alcalde de primer voto Martín de Alzaga, pero logró huir junto a Beresford a Montevideo (aún ocupada por las tropas inglesas) y luego a Río de Janeiro. A comienzos de 1808 arribó allí con la Corte portuguesa la princesa Carlota Joaquina de Borbón, quien además

9 El caso de Pueyrredón no llegó a judicializarse — ya que el implicado logró huir a Río de Janeiro-, por lo que se reconstruye a partir del expediente de acuerdos labrados por el Cabildo de Buenos Aires que Elío envió a las Cortes, y del memorial que Pueyrredón presentó en la Corte de Río de Janeiro. Todo ello se encuentra en Biblioteca de Mayo, 1960, tomo XI.

10 Por haber sido estudiados en profundidad por Barragán (2008) e Irurozqui (2011), solo se hacen breves referencias a tales movimientos a partir de los trabajos de dichas autoras.

11 Este trabajo sigue las pistas metodológicas de Pierre Rosanvallon en su propuesta de hacer una historia «de la manera como una época, un país o unos grupos sociales procuran construir respuestas a lo que perciben más o menos confusamente como un problema, y hacer la historia del trabajo efectuado por la interacción permanente entre la realidad y su representación, definiendo campos históricos-problemáticos» (Rosanvallon, 2002, 129). Además del autor citado, este artículo se nutre de los aportes realizados por el equipo de investigadores iberoamericanos liderado por Javier Fernández Sebastián (2009 y 2014) y de los estudios sobre los lenguajes políticos de José Carlos Chiaramonte (1997) y Noemí Goldman (2008). 
de esposa del príncipe regente, futuro João VI, era la hija mayor de Carlos IV y hermana de Fernando VII, rey de España. Cuando se conocieron en Brasil las noticias sobre el motín de Aranjuez en marzo y los sucesos de Bayona en mayo, la princesa se transformó en la nueva esperanza abrigada por Rodríguez Peña.

En adhesión al manifiesto que Carlota Joaquina firmó reclamando la regencia de América por ser la legítima heredera del depósito de la soberanía vacante, Rodríguez Peña redactó una circular en la que pregonaba que la proclamación de la princesa como regente era la única manera de alcanzar la «independencia de la patria»y enfrentar «la inesperada mutación» ocasionada en España por la ocupación de Napoleón. ${ }^{12}$ Diego Paroissien, un joven médico inglés que a comienzos de noviembre de 1808 abordó una fragata con destino a Buenos Aires, distribuiría copias de la circular y cartas destinadas a posibles partidarios del proyecto. Pero la fragata atracó en Montevideo y los pliegos cayeron en manos del gobernador Francisco Javier de Elío, que ordenó la detención de Paroissien, la confiscación de sus bienes y el inicio de un sumario.

Elío informó sobre el incidente a Liniers, quien por su parte designó como juez comisionado al oidor Manuel de Velasco. El gobernador remitió el expediente pero mantuvo prisionero a Paroissien, obstaculizando la rápida resolución del proceso al impedir la toma de declaración de uno de los principales imputados. La renuencia de Elío obedeció sin duda al enfrentamiento abierto que mantenía con el virrey desde la impugnación de su autoridad (bajo la acusación de ser partidario de Napoleón Bonaparte) y la formación de la Junta de Montevideo en septiembre de 1808.

Ana Frega señaló que la Junta emergió como expresión de la antigua rivalidad jurisdiccional y la competencia por mayores privilegios con la capital virreinal. La crisis peninsular disparó en los comerciantes montevideanos el temor a perder su preeminencia en la intermediación de los circuitos mercantiles, pero les ofrecía también la oportunidad de controlar recursos y lograr autonomía en la toma de decisiones. Junto a militares, curas y letrados, apostaron por la Junta de Elío y buscaron fortalecer su vínculo con los comerciantes europeos monopolistas liderados por Alzaga, cuyo descontento con el virrey databa desde hacía tiempo. A pesar de ser reprobada por la Audiencia y el obispo de Buenos Aires, el gobernador de

12 «Circular de Saturnino Rodríguez Peña, proponiendo a la infanta Carlota Joaquina para que ocupe la regencia de las posesiones españolas en América. Río de Janeiro, 4 de octubre de 1808», Biblioteca de Mayo, 1960, XI, 10249-10251. 
Potosí y parte de la Marina, la Junta montevideana no fue reprimida y mantuvo su posición hasta junio de 1809, cuando se desintegró por orden de la Junta Central Suprema y Gubernativa. ${ }^{13}$

Las diligencias del proceso se reactivaron por lo tanto con la disolución de la Junta de Montevideo y el arribo a Buenos Aires en julio de 1809 del nuevo virrey designado por la Junta Central, Baltasar Hidalgo de Cisneros. Dispuesto a liquidar las disputas y castigar cualquier conato sedicioso o revolucionario, Cisneros exigió a Elío el traslado a la capital de Paroissien para concluir el juicio. El acusado compareció ante el juez a comienzos de octubre de 1809 y declaró que su relación «con el dicho Peña no [había] sido estrecha», pero manifestó saber por «voz común, que había profugado con Beresford», y que había estado «complicado en un sistema de independencia». Alegó desconocer a los partícipes del plan, «a excepción de la señora infanta y almirante Sydney Smith», y afirmó que su actuación representaba «un grande servicio al rey de España, y a toda la nación», porque con la regencia de Carlota Joaquina se evitarían «la anarquía y desorden» y la «usurpación que intentarían los franceses». ${ }^{14}$

En noviembre de 1809 el fiscal del crimen de la Audiencia, Antonio Caspe y Rodríguez, imputó a los acusados por el delito de «alta traición». ${ }^{15}$ El cargo era de suma gravedad puesto que había pretendido «trastornar el orden, y promover la anarquía» y había injuriado a Carlota al suponerla «cómplice y auxiliar de un crimen enorme contra su augusto hermano». El fiscal solicitó la pena capital «para satisfacción de la vindicta pública y en desagravio de la señora infanta». ${ }^{16}$ Cabe destacar que la invocación del fiscal a Carlota Joaquina era un argumento instrumental al proceso - dada la investidura dinástica de la infanta-, que no debe ocultar las serias sospechas que las autoridades coloniales tenían sobre la Corte de Braganza. ${ }^{17}$

Rodríguez Peña, considerado autor del crimen y acusado también de «infidencia», se encontraba en Río de Janeiro y, a pesar de la solicitud de

13 Frega, 2007.

14 «Sumario instruido a Diego Paroissien por ser portador de correspondencia de Saturnino Rodríguez Peña. Montevideo, 7 de septiembre de 1807, Buenos Aires, 31 de marzo de 1809», Biblioteca de Mayo, 1960, XI, 10335-10337. William Sydney Smith era el almirante a cargo de la escuadra inglesa en Brasil y quien había organizado el traslado de la Corte de Braganza desde Lisboa. Fue uno de los principales impulsores del proyecto de regencia de Carlota Joaquina en el Río de la Plata.

15 Ibidem, 10339-10341.

16 Idem. 2015 .

17 Para un estudio sobre las tramas urdidas alrededor de Carlota Joaquina, véase Ternavasio, 
Liniers a Carlota, nunca fue enviado a Buenos Aires. ${ }^{18}$ Fue Paroissien quien presentó en marzo de 1810 un memorial tras la acusación. La estrategia de la defensa, elaborada por el abogado Juan José Castelli, buscó demostrar la inexistencia de delito en los documentos escritos por Rodríguez Peña e incautados a Paroissien. ${ }^{19}$ Para ello Castelli distinguió las ideas de Rodríguez Peña en 1806 y en 1808. Durante la ocupación inglesa en Buenos Aires, reconoció que había cometido un delito al «fomentar la independencia», es decir, al anhelar «desmembrar la América de la Corona de Castilla». En cambio, la «independencia política» que pregonaba su «plan moderno» proponía:

que ocupada España por los franceses, la América conserve en sí la casa reinante propia que es la de Borbón; que proclame la regencia en la más próxima persona real libre, y heredera, con separación e independencia de potencia extraña, disponiéndose a arreglar su gobierno sin variación de dinastía, ni introducción de otra nueva; que aleje los partidos de sistemas perniciosos, turbulentos, revolucionarios, y sanguinarios, y que recabe la unidad y espíritu público en todos los reinos de América. ${ }^{20}$

Castelli procuró despejar el aura criminal del proyecto de Rodríguez Peña vinculando la idea de independencia a la de americanización de la monarquía. La hipótesis de que España caería bajo dominio francés justificaba la separación de los territorios americanos porque de ese modo se mantendría a salvo el patrimonio del rey. Frente a la imposibilidad de imitar la maniobra lusitana de trasladar la Corte - todos los miembros varones de la familia real eran prisioneros de Napoleón-, debía recurrirse a otra alternativa para conservar la monarquía española en América: la regencia de Carlota Joaquina. La tríada planteada entre la separación de los territorios americanos, la conservación de la monarquía a partir de su americanización y la regencia de la infanta se asentaba además sobre el principio del linaje dinástico. Dicho principio servía a Castelli para dotar de legalidad y legitimidad a las ideas «independentistas» de sus defendidos en el desconcierto

18 Si bien la figura de «infidencia» no hacía referencia a un delito concreto, fue utilizada para criminalizar a los vasallos rebeldes en América y a los colaboradores de los franceses en la Península. Ortelli, 2004.

19 Juan José Castelli era un abogado porteño que ejerció como secretario del Consulado de Comercio e integró el grupo que apoyó el proyecto carlotista. En 1810 se plegó a la Revolución: participó como vocal en la Junta formada el 25 de mayo, ejecutó a los contrarrevolucionarios de Córdoba y lideró el Ejército Auxiliar del Perú. Debido a la derrota militar de Huaqui en junio de 1811 fue sometido a juicio, pero murió en 1812 antes de su resolución. Wasserman, 2011.

20 «Sumario instruido a Diego Paroissien», cit. en nota 14, 10355. Noemí Goldman (2009) también examinó la voz «independencia» en el alegato de Castelli. 
que supuso la vacatio regis, cuya excepcionalidad disparó a su vez una vacatio legis al no estar contemplada respuesta alguna dentro del orden legal de la monarquía. ${ }^{21}$

Para reforzar su argumento, el abogado señaló que, como consecuencia de la desaparición del monarca, las autoridades coloniales carecían de fundamento para gobernar sus jurisdicciones, y que la Junta Suprema de Sevilla se había arrogado una representación «sin autoridad», por lo que podía ser «tan legítima» como las «juntas que pretendieron ejercerla en América». ${ }^{22} \mathrm{El}$ cuestionamiento hacia al juntismo partía del reconocimiento de cierto viso disruptivo: aunque se basaba en el principio de la retroversión de la soberanía a los pueblos de la tradición jurídica hispánica, había derivado en la formación de gobiernos locales autónomos y en la dispersión territorial de la soberanía. ${ }^{23}$ La regencia de la infanta en tierras americanas funcionaría como un freno a la instalación de «una forma democrática, aristocrática u otra republicana popular» y como un símbolo de «unidad» frente a la proliferación de juntas con aspiraciones autonómicas que violentaban el «orden y régimen de la constitución fundamental del reino». ${ }^{24}$

Aunque basado en argumentos jurídicos, el alegato en favor del derecho al trono de Carlota pretendió apuntalar la posición política adoptada por el grupo ilustrado del que formaban parte Rodríguez Peña y el propio Castelli. Este grupo vislumbró en la regencia la posibilidad de reformar el gobierno colonial y la propia monarquía: en sus documentos Rodríguez Peña anunciaba que el «nuevo gobierno» se acordaría mediante la convocatoria a Cortes para propiciar las «mejoras de gobierno, leyes, constituciones» como en la Península. El paralelismo entre la regencia y la labor de la Junta Central, y luego de las Cortes, sumaba otro elemento discursivo para despejar dudas sobre la intención fidelista del plan promovido por Rodríguez Peña.

Desde la historia conceptual se ha señalado que el término «independencia» (que en su nivel léxico refería a la «potencia o aptitud de existir u

21 Annino, 2008. A partir del estudio de una conspiración tramada en 1809 en Nueva España, Alfredo Ávila (2003) señaló que, debido a la crisis experimentada a partir de 1808, ninguna de las posiciones políticas defendidas contaba con la suficiente legitimidad — real pero también divinacomo para imponerse sobre las otras.

22 «Sumario instruido a Diego Paroissien», cit. en nota 14, 10351.

23 Annino, 2008. Sobre la crisis de la monarquía y la federalización de la soberanía, remitimos a Portillo Valdés, 2002.

24 «Sumario instruido a Diego Paroissien», cit. en nota 14, 10346. 
obrar de alguna cosa necesaria y libremente, sin dependencia de otra» $)^{25} \mathrm{se}$ politizó a partir de las revoluciones norteamericana y francesa, ligándose a los conceptos de libertad y soberanía. En el mundo hispánico, la crisis de 1808 profundizó dicha politización, aunque en el Río de la Plata, como advirtió Alejandra Pasino, las invasiones inglesas de 1806 y 1807 impactaron en el término. La politización así como también la polisemia que «independencia» adquirió durante la coyuntura se advierten en la defensa de Castelli. Así, el término era utilizado en sentido negativo para señalar los objetivos de los grupos criollos que ansiaban destituir autoridades coloniales y cortar el vínculo con la metrópoli, y en sentido positivo, para referirse desde 1808 a la lucha contra los franceses. Su uso ambiguo hacía imprescindible que fuese especificado para evitar que su sentido se prestara a confusión y, por ende, que los diversos planes «independentistas» de Rodríguez Peña fuesen mal considerados. ${ }^{26}$ Poco tiempo después se produjo el estallido revolucionario de mayo de 1810. Paroissien pidió a la Junta Provisional de Gobierno —en la que Castelli ejercía como vocal— su liberación, que le fue otorgada por decreto el 14 de julio de $1810 .{ }^{27}$

\section{Las «escandalosas» cartas de Juan Martín de Pueyrredón}

Juan Martín de Pueyrredón desempeñó un papel destacado durante la reconquista de Buenos Aires en 1806, por lo que el cabildo abierto celebrado en agosto de ese año (en el que se delegó el mando militar y político del virreinato en Liniers) lo envió a España para informar al rey de los méritos que la ciudad había obtenido en su lucha contra los ingleses. En marzo de 1808, cuando se encontraba a punto de retornar de España, el motín de Aranjuez y las abdicaciones de Bayona demoraron su regreso y lo convirtieron en un observador privilegiado de la crisis de la monarquía española. Forzado a permanecer en la Península, Pueyrredón despachó varias cartas al Cabildo capitalino relatando sus impresiones sobre los inusitados acontecimientos. En ellas pintó un panorama desalentador, en el que se

25 Citado en Pasino, 2014, 33.

26 Pasino, 2014, 26.

27 Paroissien hizo carrera como médico cirujano en el Ejército Auxiliar del Perú dirigido por Castelli y el Ejército de los Andes y obtuvo, además, una de las primeras cartas de ciudadanía de las Provincias Unidas del Río de la Plata por decreto de la Asamblea del año XIII. Saturnino Rodríguez Peña regresó en 1814 a Buenos Aires y ocupó cargos civiles y militares, pero en 1815 cayó en desgracia tras el derrumbe del gobierno directorial encabezado por Carlos María de Alvear. 
evidenciaba la situación delicada que atravesaba la monarquía, pero también cómo el concepto de soberanía se convirtió en el motor de la crisis debido al surgimiento de diversos cuerpos que la disputaban: ${ }^{28}$

\begin{abstract}
El reino dividido en tantos gobiernos cuantas son sus provincias: las locas pretensiones de cada una de ellas a la soberanía, el desorden que en todos se observan y las ruinas que les prepara el ejército francés que aunque rechazado en sus primeras tentativas se ha replegado a Burgos en donde recibe continuos esfuerzos, son consideraciones que me impiden permanecer por más tiempo en el desempeño de una comisión que hoy veo sin objeto. ${ }^{29}$
\end{abstract}

Frente a la confusión imperante, Pueyrredón informó al Cabildo su decisión de retirarse de la Junta de Sevilla «por no haber en ella más facultades que en las demás». ${ }^{30}$ Vaticinó que la dispersión territorial de la soberanía que había provocado la vacatio regis no encontraría solución en la formación de una Junta Central y Suprema, pues la «reunión monstruosa» que se preparaba chocaría con el ánimo de las provincias que querían «sostener cada una su soberanía y ser absolutas en su departamento». ${ }^{31}$ Por último, advirtió que las «esperanzas lisonjeras» recibidas por medio de otros conductos eran «irrealizables en la actual situación política» y aconsejaba que como «todos» deseaban «la herencia de ese rico territorio [...] una prudente detención» era el mejor «partido» ofrecido por «la razón». ${ }^{32}$

Sin duda que, como testigo presencial, Pueyrredón realizaba un diagnóstico muy certero y lúcido de la situación que experimentaba España y por ello recomendaba a las autoridades locales prudencia y «detención». Pero para el cuerpo capitular, las «escandalosas» cartas de su «ex diputado» daban cuenta «de una infame adhesión al emperador de los franceses, o de ideas corrompidas por la independencia», cuyo propósito era «inducir la división de estos territorios» y romper «la unión con la metrópoli». Esta interpretación del cuerpo capitular no era ajena a los realineamientos de fuerzas internas producidas en el virreinato durante esos meses y daba cuenta, una vez más, de la suspicacia con la que las autoridades coloniales evaluaron la actuación de los grupos criollos durante la crisis, catalogándolos como

28 Goldman, 2014, 21.

29 «Expediente obrado con motivo de las cartas escritas desde Cádiz por don Juan Martín de Pueyrredón al Cabildo de Buenos Aires y la detención de aquel a su arriba a este puerto. Málaga, 22 de agosto de 1807, Montevideo, 5 de enero de 1809», Biblioteca de Mayo, 1960, XI, 10371.

30 Idem.

31 Ibidem, 10373.

32 Ibidem, 10372. 
«independentistas» en el sentido de «secesionistas». ${ }^{33}$ Para el Cabildo, lo que generaba más alarma era el «abismo de males» que la difusión de tales noticias podía acarrear, por lo que, ante el inminente regreso de Pueyrredón, pidió a Elío que impidiese su desembarco, interceptara sus papeles y lo remitiera bajo partida de registro a disposición de la Junta Central, que para ese entonces ya se había conformado. ${ }^{34}$ Las desesperadas tentativas por evitar la circulación de información sobre los sucesos de la Península manifestaban el pánico que las autoridades virreinales experimentaron frente al juntismo en España y, a la vez, la asincronía de los acontecimientos ocurridos a ambos lados del Atlántico. ${ }^{35}$

A comienzos de 1809, cuando recaló en Montevideo, Pueyrredón fue apresado por Elío y su equipaje requisado. La inspección reveló pasaportes, una nota del cargamento que transportaba la fragata y varios documentos ocultos en un baúl que dispararon las sospechas. El primero de ellos, titulado «Artículos de fe», carecía de firma y destinatario, y su contenido era bastante confuso. El segundo era una proclama escrita por Pueyrredón en Cádiz y destinada al Primer Escuadrón de Húsares de Buenos Aires, cuerpo miliciano del que había sido comandante:

Mi residencia en España siempre fue inútil. Hoy con más motivos lo es por la revolución y trastornos políticos que padece. [...] La Europa se aniquila y desola con guerras y conquistas [...] Ignora sin duda; e ignoran todos el fuego eléctrico que corre en nuestras venas. Ya desaparecieron aquellos siglos felices para hacer el juguete de esos puntos, y sus habitantes. Sí compatriotas: La América meridional ocupa la atención de este antiguo mundo. Juzgan su apatía, debilidad e ignorancia para disponer de ella, como de una cosa inerte. ${ }^{36}$

En esta proclama, además de definir los sucesos españoles como una «revolución» apelando al cariz negativo del concepto —un concepto que los propios peninsulares utilizaron para describir la experiencia surgida de la lucha contra Francia-, Pueyrredón cuestionaba la imagen de América como un mayorazgo «inerte»y sin voluntad propia. ${ }^{37}$ Dicho cuestionamiento expresaba la creación de una comunidad que, a pesar de su falta de consistencia jurídica, se presentaba como un polo de identificación co-

33 San Francisco, 2014, 18.

34 «Expediente obrado con motivo de las cartas», cit. en nota 29, 10373-10374.

35 Ternavasio, 2010a.

36 «Expediente obrado con motivo de las cartas», cit. en nota 29, 10379-10380.

37 Goldman, 2009, 72. 
existente con otras identificaciones, entre ellas la española. ${ }^{38}$ En relación al «patriotismo criollo», Gabriel Entin destacó que durante la colonia, los miembros de las elites urbanas invocarían a América como patria distinta a España con la intención de modificar políticas reales consideradas perjudiciales para las ciudades hispanoamericanas. De esta manera se reforzó un desdoblamiento del bien común entre la parte europea y americana de la monarquía ${ }^{39}$ Lo americano surgió como una forma de identidad que, a pesar de asumirse de manera integrada en lo hispano, denunciaba ya en su origen una oposición a lo español. Una identidad que, como expuso José Carlos Chiaramonte, se reforzó en el Río de la Plata durante las invasiones inglesas, debido a la creación de cuerpos armados criollos que acrecentaron la conciencia patriótica y la necesidad de expresar la distancia respecto de lo español. ${ }^{40}$ Mientras tanto en la Península, desde el último cuarto del siglo XVIII, en una especie de contra espejo, la redefinición de los conceptos de patria y nación españolas (que en su sentido político más amplio referían al conjunto de los súbditos de la Corona) ${ }^{41}$ también era objeto de debate, una redefinición que para los letrados peninsulares excluía literalmente a América. ${ }^{42}$

A mediados de febrero de 1809, Elío envió el expediente a la Junta Central y embarcó a Pueyrredón rumbo a España, pero no llegó a destino, ya que su navío fue azotado por una tempestad y obligado a anclar en las costas de Brasil. Dos meses después, la Junta Central ordenó al gobernador de Montevideo apresar a Pueyrredón, iniciarle una causa y remitirlo nuevamente a España por su intento de «desacreditar el gobierno español calumniándolo del modo más infame con miras muy criminales» ${ }^{43}$ La manera en la que se condujo Elío, sin notificar al virrey ni a la Audiencia, y entendiéndose directamente con el Cabildo de Buenos Aires y con la Junta Central, constituye una prueba más de las disputas que mantenían las autoridades coloniales y la autonomía con la que buscaban actuar. ${ }^{44}$

38 Entin, 2013.

39 Ibidem. Para el tema del patriotismo criollo, citamos a Brading, 1991.

40 Chiaramonte, 1997, 71-75.

41 Sobre las mutaciones del concepto nación véase Souto y Wasserman, 2008.

42 Portillo Valdés, 2009.

43 «Borrador de Real Orden de la Junta Central a Javier Elío; reclama la captura y remisión a España de Juan Martín de Pueyrredón por el delito de desacreditar al gobierno español con su carta abierta al Cabildo de Buenos Aires. 9 de abril de 1809», Mayo documental, 1962, VIII, 192.

44 Ternavasio, 2010a. 
Aprovechando el atraque forzoso, Pueyrredón se fugó y se embarcó en un navío portugués, que arribó a Buenos Aires el 5 de julio de 1809, casi simultáneamente con Cisneros. Pueyrredón se entregó a las autoridades y quedó detenido en el cuartel de Patricios. Según el Cabildo, participó de las reuniones organizadas allí para oponerse a la toma de posesión del cargo por parte del nuevo virrey, quién permaneció durante un tiempo en la Banda Oriental. La designación de Cisneros, la orden de que Liniers se trasladara a la Península y la tolerancia mostrada frente a la desobediencia de la Junta de Montevideo y de Elío (que fue «premiado» con el cargo de inspector de armas ${ }^{45}$ habían provocado malestares entre los comandantes de milicias de Buenos Aires. Pero para el cuerpo capitular, la intención de sostener a Liniers y, por lo tanto, la «oposición a los soberanos mandatos de la Suprema Junta», manifestaba el objetivo de «evadirse de la dominación española, y aspirar a la independencia total de estos dominios». ${ }^{46}$

A fines de julio de 1809, ante la llegada de Cisneros a la capital y temiendo correr la misma suerte que con Elío en Montevideo, Pueyrredón escapó del cuartel de Patricios hacia Brasil y se instaló en Río de Janeiro. Convertido en un agente de la infanta Carlota Joaquina, presentó en la Corte su «fiel exposición» en la que relató su conducta pública desde 1806 con la intención de reivindicarse frente a las acusaciones de la Junta de Montevideo y del Cabildo de Buenos Aires. ${ }^{47}$ Además de repasar los servicios realizados en favor del rey y su misión como diputado en representación del cabildo, narró su periplo en la Península luego de la prisión de Fernando VII, la decisión de retornar a América, su detención en Montevideo y posterior embarque a la Península, el naufragio en las costas brasileñas y el regreso a Buenos Aires con la consecuente prisión en el cuartel de los Patricios, la aparición en escena del virrey Cisneros, su fuga y asilo en la Corte de Brasil.

En su defensa, Pueyrredón sostuvo además que los papeles hallados entre sus pertenencias no constituían prueba suficiente para su arresto.

45 Debido a la oposición de las milicias criollas, Cisneros aceptó que Liniers permaneciese en el Río de la Plata, y que Elío no tomara posesión de su cargo. Frega, 2007.

46 «Acuerdo del Cabildo de Buenos Aires, en el que se dio cuenta de las reuniones celebradas por los jefes militares con respecto a la llegada del virrey Baltazar Hidalgo de Cisneros. Buenos Aires, 13 de julio de 1809», Biblioteca de Mayo, 1960, XI, 10397.

47 «Fiel exposición que hace don Juan Martín de Pueyrredón de su conducta pública desde el año 1806 hasta el presente de 1809 en vindicación de la nota en que lo deben haber puesto los insultos hechos a su persona por la Junta de Gobierno de Montevideo. 1809», Biblioteca de Mayo, 1960, XI, 10383-10394. 
Y agregó que, mientras permaneció detenido, solo había sido informado por Elío «verbalmente y en conferencia particular» de que las cartas escritas al Cabildo de Buenos Aires constituían su «delito». ${ }^{48}$ Sin embargo, Pueyrredón era consciente de que su caso había quedado en la línea de fuego del enfrentamiento que mantenían las autoridades porteñas entre sí y en el posicionamiento que las montevideanas habían adoptado en dicha rivalidad. Pueyrredón permaneció en Río de Janeiro hasta junio de 1810, cuando regresó a Buenos Aires y se adhirió a la revolución. Las acusaciones en su contra, por supuesto, quedaron sin efecto. ${ }^{49}$

\section{La «junta subversiva» del $1 .^{\circ}$ de enero de 1809}

El $1 .^{\circ}$ de enero de 1809 , en ocasión de la renovación de los capitulares, el Cabildo porteño - liderado por el comerciante vizcaíno Martín de Alzaga - intentó destituir al virrey Santiago de Liniers y constituir una junta movilizando a los tercios de Gallegos, Miñones de Cataluña y Vizcaínos y a un número de españoles peninsulares. Liniers se rehusó a aceptar la formación de una junta, pero ante la presión se reunió con los oidores y propuso dimitir de su cargo. La Audiencia, en un esfuerzo por garantizar la legalidad, le advirtió que su renuncia provocaría atentados contra las demás autoridades. La presencia de algunos batallones rodeando la plaza (entre ellos el de Patricios, cuyo comandante era Cornelio Saavedra) selló, sin embargo, el fracaso del movimiento. Los tercios que habían apoyado al intento juntista fueron disueltos. Los responsables del motín, Martín de Alzaga, Juan Antonio Santa Coloma, Olaguer Reynals, Francisco de Neyra y Arellano y Esteban Villanueva fueron detenidos y desterrados a Carmen de Patagones, de donde se fugaron en un navío enviado por el gobernador de Montevideo.

El intento juntista exhibió la inestabilidad que atravesaba no solo el más joven de los virreinatos americanos, sino toda la monarquía española. Entre 1808 y 1809, en distintas ciudades americanas se formaron juntas — siguiendo el ejemplo español— como respuesta a la crisis peninsular, pero para las autoridades eran secesionistas y subversivas ya que

48 Ibidem, 10390.

49 Pueyrredón tuvo una intensa trayectoria revolucionaria y ocupó una variedad de cargos políticos, entre los que se destaca su desempeño como Director Supremo de la Provincias Unidas entre 1817 y 1819 . 
consideraron que sus intenciones eran deponer al gobierno para formar uno propio, por lo que buscaron desalentarlas o directamente reprimirlas. Desbaratada la iniciativa del Cabildo, Liniers condenó a los capitulares en una proclama puesto que habían pretendido:

establecer la confusión y el desorden para trastornar los sagrados principios de nuestra constitución monárquica, queriendo erigir una junta subversiva, y enteramente opuesta a la autoridad soberana de nuestro muy amado rey y señor don Fernando VII, intentando implicar en este pérfido proyecto al pueblo de Buenos Aires. ${ }^{50}$

El virrey desterró a los acusados y nombró al capitán de fragata Juan de Vargas y al coronel de artillería Francisco Agustini como jueces fiscales. La decisión de seguir la causa en el fuero militar se fundamentó en que la «sedición» había sido «fomentada y sostenida por individuos de los cuerpos militares» y conducida «contra la seguridad de la real fortaleza». Aunque la naturaleza del delito podía corresponder a la justicia ordinaria — su objeto había sido el de «trastornar el actual sistema de gobierno»-, no existen indicios de reclamaciones por parte de la Audiencia para entender en la causa, mostrando así la voluntad de mantenerse al margen de un conflicto en el que se encontraban involucrados, en posiciones enfrentadas, el virrey y miembros del cabildo y personas cercanas a dicho cuerpo.

La fuga de Patagones constituyó una muestra más de las tensiones y roces que jalonaron la relación entre el virrey Liniers y el gobernador Elío. El rescate de los capitulares no fue la única gestión referida al episodio que Elío realizó: también encomendó al alcalde de primer voto del Cabildo de Montevideo recabar información sobre los sucesos de la capital para anoticiar a la Junta Central en España, ya que varios oficiales de los cuerpos de Vizcaínos, Catalanes y Gallegos habían llegado a la ciudad «huyendo de la persecución y opresión del virrey». En el expediente, todos los testigos señalaron a los ediles como defensores de la «causa justa», «padres de la patria» $\mathrm{y}$ «fieles españoles», y cuestionaron al virrey por su origen - asegurando que «no querían ser gobernados por un francés» cuyas acciones eran sospechosas «de ser contrarias a los intereses del Rey y la patria»-, pero también por los desórdenes que había causado «su mala administración». Además de cuestionar la autoridad virreinal, los declarantes explicaron que la junta que habían solicitado respondía a la intención de «conservar» para Fernando VII el «patrio suelo», y que esta se hubiera realizado con «el

50 «Proclama de Liniers de enero de 1809», Biblioteca de Mayo, 1960, XI, 10414. 
mismo orden que en España, y algunos de los establecimientos ultramarinos», es decir, «sujeta a la central, o a quien representase la nación». En las declaraciones de los oficiales que reivindicaron el intento juntista se observa cómo la noción de «nación» española se superponía a los distintos significados de «patria». Los testigos se refirieron a quienes lideraron el fracasado movimiento del $1 .^{\circ}$ de enero de 1809 como «padres de la patria», una expresión común durante el período colonial para nombrar a los miembros del cabildo, que remitía al lugar de origen, Buenos Aires en este caso. Pero apelaron asimismo a una acepción más general y difícil de delimitar espacialmente, que poseía cierta connotación sentimental. Según Gabriel Di Meglio, la noción de «patria» se ubicaba como parte de una tríada de elementos fundamentales de la monarquía española junto al rey y la religión. En esa tríada, no se establecía bien cuál era la patria (podía comprender el virreinato, la América española o toda la monarquía) porque se trataba de un principio, de un elemento casi sagrado. La «patria» era, en este sentido, la comunidad amplia en la que se había nacido o se vivía. ${ }^{51}$ Así, el amor a esa «patria» exigía el deber de preservar el orden y el bienestar general, y fue en ese deber para con el rey y la patria que los oficiales que testificaron encuadraron las acciones de los capitulares. No podían decir lo mismo de las reuniones que se realizaban en Buenos Aires antes de la creación de la Junta de Montevideo y que tenían por fin tratar, «según la voz general», «la independencia» de la «provincia». ${ }^{52}$

Con la apertura del expediente y su envío a la Península, una vez más Elío buscó sacar provecho de la convulsionada coyuntura: en la medida en que, producto de las declaraciones referidas a la asonada del $1 .^{\circ}$ de enero, quedara desacreditada la figura de Liniers y demostrada la validez de los motivos esgrimidos por el Cabildo, la propia actuación del gobernador y de la Junta que encabezaba podría obtener el beneplácito de las autoridades peninsulares. Bajo la protección de Elío, los capitulares redactaron un memorial para defenderse de la acusación de ser «autores de una insurrección o rebelión proyectada contra la patria». En el escrito manifestaron su sorpresa ante lo que les parecía evidente luego del inicio del proceso juntista español:

51 Di Meglio, 2008, 115-129.

52 «Testimonio del expediente actuado por el juzgado de primer voto de esta ciudad a virtud de la comisión de su Junta gubernativa sobre los sucesos públicos ocurridos en Buenos Aires el 1..$^{\circ}$ de enero del presente año de 1809», Biblioteca de Mayo, 1960, XI, 10642. 
Porque aun concedido que se aspirase a una junta de gobierno, ¿en qué alteraba esto los principios fundamentales de nuestra constitución monárquica? ¿Deja de serlo por ventura la que nos rige felizmente bajo la protección científica de la suprema Central de España y de las Indias? ¿Por qué se ha de atribuir insurrección al deseo de uniformar el gobierno? ${ }^{53}$

Si la intención de formar una junta había sido «uniformar» la situación americana a la peninsular, lejos estaba de alterar los principios monárqui$\cos \mathrm{y}$ «pregonar la independencia». Los acusados agregaron que esas maniobras eran perpetradas por hombres capaces de arrastrar «por su poder, autoridad y valimiento popular» a la «turba de los pérfidos sin principios de educación, ni sentimientos de religión», y si existía alguien capaz de ello, ese era Liniers. El desenlace de la jornada del $10^{\circ}$ de enero era una prueba indiscutible del argumento; por eso, y por el «principal papel» representado en el episodio, recusaron a los fiscales designados por el virrey. ${ }^{54}$

Al igual que lo sucedido con la causa contra Rodríguez Peña y Paroissien, la llegada del virrey Cisneros destrabó el proceso contra los responsables del intento juntista. Debido a las repetidas recusaciones a los fiscales Vargas y Agustini, Cisneros designó otros dos jueces, el teniente de navío Domingo Navarro y el teniente de fragata Joaquín de Sagasti. Los nuevos jueces elevaron un informe al virrey sobre el estado de la causa, estancada porque los capitulares refugiados en Montevideo aún no habían sido interrogados. En su opinión, no existían pruebas contundentes contra los acusados, aunque reconocieron cierta ambigüedad en su conducta debido a las públicas desavenencias que tenían con el virrey. También señalaron como causas del «tumulto» los «sucesos de la metrópoli» —que habían influido en la animadversión contra Liniers, porque la invasión napoleónica había habilitado «a todo buen patricio a odiar el nombre francés»— y las «vicisitudes extraordinarias» de la capital en los últimos años. Finalmente, consideraron que

el suceso del referido dia acaecido en esta capital no fue una traicion al Estado con objeto de segregarse de la dominacion soberana, en cuyo caso ninguna piedad, ninguna

53 «Memorial suscrito por Martín de Alzaga, Olaguer Reynals, J.A. Santa Coloma, Francisco de Neyra y Arellano y Esteban Villanueva, dirigido al virrey interino Santiago de Liniers, replicando el contenido de la proclama del 4 de enero, a la que tachan de libelo, y recusándolo para intervenir en la causa que se les sigue. Montevideo, 24 de febrero de 1809», Biblioteca de Mayo, 1960, XI, $10513-$ 10514.

54 Idem. 
consideración debiera tener. Fue un arrebato involuntario en muchos, una pasion, y ceguedad en otros que les hizo concebir ideas de desconfianza en el govierno. ${ }^{55}$

Cisneros remitió la causa y el informe a los asesores Mariano Moreno y Julián de Leyva para que estudiasen el caso. Moreno había apoyado el movimiento encabezado por Alzaga, era abogado del Cabildo y tenía una consideración negativa sobre el gobierno de Liniers. ${ }^{56}$ Los asesores sostuvieron que no existía materia más complicada que definir las penas correspondientes a «los movimientos populares», ya que era preciso «meditar con la mayor atencion la qualidad, u numero de complices», así como también «el fin à que se dirigieron» y especialmente las consecuencias que podían resultar de la imposición de los castigos. Moreno y Leyva marcaron un paralelismo con el motín de Aranjuez para ilustrar el dilema planteado. La equiparación de la cuestionada situación de Liniers con la de la odiada figura del ministro Godoy, permitía a Moreno y a Leyva, además, atenuar la gravedad de la asonada. ${ }^{57}$ Con el objetivo de fortalecer el razonamiento de que los fines determinaban la criminalidad (o no) de este tipo de movimientos, recurrieron también a la destitución del virrey Sobremonte, como situación precedente en la que sus autores no habían sido castigados:

ni la integridad y justificación de la Real Audiencia en quien recayó el mando del Virreynato ni el monarca enterado de tan extraordinario acaecimiento pensaron en su castigo, y sin duda, porque las intenciones del pueblo que aclamaba por la deposicion de un gefe que le era sospechoso, no se contemplaron como delinquentes, ni como opuestos à la subordinacion y obediencias devidas á la autoridad del govierno. ${ }^{58}$

Moreno y Leyva concluyeron que los episodios referidos habían sido consecuencia «de un zelo exaltado de fidelidad al monarca», y no de la intención de poner fin a «la subordinación devida al soberano, y à la metrópoli», por lo que recomendaban una amnistía general. ${ }^{59}$ La sugerencia fue atendida por Cisneros, ya que en septiembre de 1809 cerró la causa,

55 «Copia de autos labrados sobre la causa formada con motivo de los sucesos de Buenos Aires, del 1. ${ }^{\circ}$ de enero de 1809, especificando causas del suceso, acontecimientos principales, estado de la causa, dictamen de los asesores doctores Julian de Leyva y Mariano Moreno, y sentencia obviada en la causa por Baltasar Hidalgo de Cisneros. 1-22 de setiembre de 1809», Mayo documental, 1962, IX, 306-320; cita p. 312.

56 Goldman, 2016, 102. A partir de mayo de 1810, Mariano Moreno ocupó el cargo de secretario de Guerra y Marina de la Junta, siendo una de las figuras más radicales que impulsó la Revolución.

57 «Copia de autos labrados sobre la causa», cit. en nota 55.

58 Ibidem, 316.

59 Ibidem, 317. 
proclamó el perdón y la absolución de todos los implicados y restableció los cuerpos milicianos de Vizcaínos, Catalanes y Gallegos. ${ }^{60}$ Alzaga, Santa Coloma, Neyra y Arellano, Reynals y Villanueva abandonaron por fin Montevideo y regresaron a Buenos Aires. ${ }^{61}$

\section{La condena de las alternativas ensayadas frente a la crisis monárquica}

Las acusaciones vertidas en los procesos judiciales estudiados muestran las diferentes valoraciones que las autoridades coloniales realizaron sobre las soluciones esbozadas por diversos actores para encarar la crisis que envolvió a la monarquía española a partir de 1808. Rodríguez Peña y Paroissien fueron imputados por el delito de alta traición, un delito estrechamente vinculado al de lesa majestad. El delito de lesa majestad era definido en las Leyes de Partidas como la traición contra la persona del rey o contra sus posesiones, y podía manifestarse a partir de acciones diversas, tales como matar al rey, formar alianza con enemigos para arrebatarle el reino, promover sublevación entre los súbditos, destruir imágenes hechas en su honor. ${ }^{62}$ Implicaba una transgresión a la superioridad terrestre pero también a la celeste, puesto que la ofensa al rey (en su persona, en su majestad y en su soberanía) comportaba una infracción a un orden que era indisponible y que formaba parte de un consenso que no admitía (todavía) discusión. Constituía por lo tanto «el gran crimen» y por su gravedad no solo debía ser castigado de manera ejemplar con la pena capital sino que podía también ser imputado después de la muerte. ${ }^{63}$ En la percepción de las autoridades coloniales, la regencia de Carlota Joaquina impulsada por los acusados fue caratulada como un delito de lesa majestad: representaba un atentado dirigido directamente contra el rey debido a que su intención última era la de sustraer territorios de su dominio para situarlos además

60 «Declaración del virrey Cisneros dando por terminado el proceso iniciado con motivo de los sucesos del $1 .^{\circ}$ de enero de 1809. Buenos Aires, 22 de septiembre de 1809», Biblioteca de Mayo, 1960, XI, 10571-10575.

61 En 1812 Alzaga fue ejecutado luego de ser sindicado como uno de los líderes de una conspiración tramada en contra del Primer Triunvirato. Polastrelli, 2012.

62 Las siete partidas del rey Don Alfonso el Sabio, cotejadas con varios códices antiguos por la Real Academia de la Historia, Madrid, 1807, III, 537-542. La obra de referencia indispensable sobre el crimen de lesa majestad es Sbriccoli, 1974.

63 Barriera, 2008. 
bajo la influencia de la Corona portuguesa, tradicional rival cuya apetencia expansionista sobre el Río de la Plata era harto conocida.

La asonada del 1. ${ }^{\circ}$ de enero de 1809 se asoció en la causa judicial a los delitos de conmoción, sublevación, rebelión, sedición y revolución. Aunque estos delitos también eran contemplados como de alta traición, tuvieron una valencia acusatoria diferente.$^{64} \mathrm{La}$ gravedad del fracasado movimiento juntista residió en que pretendió sublevar al «pueblo» en contra de las autoridades constituidas, es decir, arrastrar a la ciudad al desacato y en este sentido fue parangonado con la destitución del virrey Sobremonte en 1807. Así lo reconocieron en el dictamen los abogados Moreno y Leyva, que asesoraron a Cisneros en dicha causa. El hecho de que los jueces consideraran como un agravante la intención de «implicar» en el movimiento al pueblo de Buenos Aires manifestaba cierta aprensión frente al papel desequilibrante que algunos actores comenzaron a asumir en las luchas por el poder. El rol desempeñado por las milicias durante la reconquista y la defensa de la ciudad y, más aún, su participación en el conflicto suscitado durante el $1 .^{\circ}$ de enero de 1809 , eran pruebas cabales del peso que adquirieron en las disputas del período. Las autoridades coloniales percibieron que quien detentaba algún grado de ascendiente y liderazgo sobre las milicias contaba con un factor de peso capaz de volcar la suerte a su favor en las rencillas políticas. Debido a su posición en la sociedad porteña, la influencia que los acusados tenían sobre amplios sectores fue motivo de resquemor. Alzaga, además de ser un rico comerciante y de haber ocupado el cargo de primer alcalde, mantenía estrechas relaciones con diferentes cuerpos armados de la ciudad, particularmente con el que luego sería conocido como Artilleros de la Unión, cuya formación había financiado durante la ocupación inglesa de la ciudad. Durante el intento juntista que el alcalde lideró el 1. ${ }^{\circ}$ de enero de 1809 había logrado el apoyo de tres cuerpos milicianos: Vizcaínos, Catalanes y Gallegos. Pueyrredón, por otro lado, había sido comandante del Regimiento de Húsares, al que también había asistido con recursos con ocasión de la reconquista de Buenos Aires.

Los episodios ocurridos en 1807 y 1809 fueron considerados como atentados contra las autoridades virreinales, lo que suponía en última instancia una afrenta contra el rey. Sin embargo, los diferentes desenlaces - exitoso en el primer caso, fracasado en el segundo- y los contextos en

64 Para el análisis de un caso puntual en el que una rebelión es tratada como crimen de lesa majestad puede consultarse Barriera, 2010. 
los que se resolvieron provocaron valoraciones disímiles. Lo mismo ocurrió respecto de la Junta de Montevideo y de las del Alto Perú, cuyos destinos fueron totalmente opuestos. Mientras que la primera no recibió escarmiento alguno, las segundas fueron condenadas y reprimidas (aunque desigualmente), más que por sus intenciones independentistas en sentido radical, por la afrenta que supusieron a los principios de subordinación y jerarquización de autoridades que regían el orden monárquico e imperial ${ }^{65} \mathrm{Si}$ bien la represión de los movimientos chuquisaqueño y paceño correspondía al virreinato del Río de la Plata por pertenecer a su jurisdicción, el virrey del Perú José Fernando de Abascal dirigió las operaciones debido a que sus fuerzas militares se encontraban más próximas y a la precariedad de la autoridad que detentaba Cisneros, siendo el primer virrey nombrado por la Junta Central. ${ }^{66}$

La Junta de La Plata se había formado el 25 de mayo de 1809 - luego de la deposición del presidente de la Audiencia por parte de los oidores-, declarado autónoma de Buenos Aires y reasumido el depósito de la soberanía. Sin embargo, ante la amenaza de la fuerza se disolvió y sus integrantes no sufrieron castigos severos, a pesar de ser acusados de atentar «contra la legítima autoridad del Jefe que gobernaba» y arrogarse el mando. ${ }^{67}$ En cambio, la Junta de La Paz, iniciada el 16 de julio de 1809 con la destitución de las principales autoridades y la conformación de un cabildo abierto del cual se derivaría la Junta Tuitiva, fue reprimida por las tropas de José Manuel de Goyeneche y sus miembros sentenciados a muerte luego de ser acusados de cometer el «delito de lesa majestad», de conspirar para «destruir el legítimo gobierno»e «inducir a la independencia». ${ }^{68}$

Marta Irurozqui ha señalado, en primer lugar, que la represión ejercida desde Buenos Aires y Lima contra las iniciativas políticas de La Plata y La Paz reveló el cuestionamiento de las autoridades virreinales por parte de otros cuerpos como la Audiencia y el Cabildo, pero también una lucha de influencias jurisdiccionales entre ambos espacios virreinales por el control

65 Irurozqui, 2007.

66 Barragán, 2008. Irurozqui, 2011.

67 Los impulsores de la Junta de Chuquisaca (Manuel y Jaime Zudáñez, Bernardo Monteagudo, N. Amaya, Joaquín Lemoine, D. N. Corcuera, Juan Antonio Fernández, los oidores Domingo Anivarro y Ángel Gutiérrez, el asesor Vicente Romano y el escribano de la Cámara de la Audiencia, Ángel Mariano Torres) fueron arrestados y sus bienes embargados. Irurozqui, 2011.

68 Las sentencias de muerte contra Pedro Domingo Murillo, Manuel Cossío, Juan Antonio Figueroa, Ventura Bueno, Basilio Catacora, Mariano Graneros, Melchor Jiménez, Apolinar Jaén, Gregorio Lanza y Juan Bautista Sagárnaga se ejecutaron a partir del 29 de enero de 1810. Barragán, 2008. 
sobre Charcas. En segundo lugar, la autora remarcó que los diferentes tratamientos que recibieron las juntas altoperuanas respondieron a la naturaleza de las instituciones que las habían liderado y que, en términos de depósito de la soberanía, el castigo aplicado a la Junta de La Plata fue más grave que el impartido a la de La Paz, a pesar de las ejecuciones. En el contexto de crisis de la monarquía española, la condena de la iniciativa platense impidió que una institución americana que gozaba de autoridad por delegación real y contaba con una amplia jurisdicción territorial concentrara la reasunción de la soberanía de manera legítima, dando como resultado la dispersión de la misma a través de los cabildos. ${ }^{69}$

Los casos de las juntas altoperuanas muestran la articulación de las dos valoraciones construidas alrededor de los episodios catalogados como afrentas contra el orden colonial (y en el discurso de las autoridades, también contra el orden monárquico): se enmarcaron en las acciones delictivas que buscaban incitar al «pueblo» para atentar contra las autoridades virreinales (en un contex to de disputa abierta por el poder) y, a la vez, en aquellas que propugnaban la independencia de la monarquía española. Es preciso señalar, por último, respecto de los movimientos juntistas de La Paz y La Plata, que las luchas entre las distintas autoridades coloniales se dieron en un clima de sospechas y acusaciones cruzadas en el que la figura de Goyeneche tuvo un papel central. Representante de la Junta de Sevilla, a su llegada al Alto Perú portaba manifiestos de la Corte portuguesa en los que se reclamaban los derechos de Carlota Joaquina a ocupar la regencia de la Corona española. Las dudas tejidas en torno a la adhesión de Goyeneche al carlotismo y la aceptación que su propuesta habría tenido de parte de algunas autoridades coloniales funcionaron como disparadores de los disturbios ocurridos a partir de mayo de 1809 en el espacio altoperuano. ${ }^{70}$

\section{A modo de cierre}

El debate suscitado respecto a los significados que adoptó el término «independencia» durante la crisis del orden colonial y monárquico es conocido. Algunos historiadores, entre ellos Jaime E. Rodríguez y José María Portillo, sugirieron que en los escritos de la época la palabra «independencia» debe interpretarse como «autonomía», puesto que así se comprendería

69 Irurozqui, 2011.

70 Ternavasio, 2015, 88-97. 
mejor la actuación de parte de la élite, que, más que a la ruptura con la metrópoli, aspiró a una mayor autonomía en la administración de sus asuntos. ${ }^{71}$ Retomando esta cuestión, Ana Carolina Ibarra señaló que las reiteradas menciones del vocablo durante el período habilitan a reflexionar sobre los complejos sentidos de su uso, por lo que delineó un esquema interpretativo a través del caso novohispano: mientras las autoridades españolas asociaron independencia a nociones tales como subversión, levantamiento, insurrección y afrenta al poder instituido, quienes fueron rotulados como «insurgentes» $\mathrm{o}$ «conspiradores» la ligaron al propósito de resguardar a la monarquía de Fernando VII de la dominación de Napoleón Bonaparte, quitándole así el cariz desafiante. ${ }^{72}$ Sin embargo, como advierte Elías Palti, marcar solo la polarización entre los extremos que representaban la ruptura y la autonomía conlleva el riesgo de encubrir el abanico de matices respecto del significado de «independencia». ${ }^{73}$

Los procesos judiciales estudiados en este artículo muestran, en palabras de Javier Fernández Sebastián, «la amplia gama de significados y el margen de ambigüedad» que permitía a los actores «usar de manera innovadora, incluso contradictoria, las mismas palabras», en este caso, «independencia». ${ }^{74}$ Una gama de significados que responde también al carácter referencial del concepto y a su posición relativa: la dependencia o la independencia siempre se definen en relación a un tercero. Por lo tanto, respecto al campo político, se trata de un «concepto bifronte», como lo definió Alejandro San Francisco, en términos de aceptación o de rechazo. ${ }^{75}$ De esta manera, las autoridades coloniales españolas moldearon negativamente su contenido atendiendo a las diversas alternativas proyectadas en el Río de la Plata a partir de 1806 para sobrellevar la crítica situación del orden virreinal y monárquico. El «delito de independencia» fue utilizado como acusación contra quienes pretendieron la separación de los territorios del dominio del rey, pero también contra aquellos que propugnaron la disolución del vínculo colonial bajo la protección inglesa, la destitución de autoridades consideradas ilegítimas, el proyecto carlotista y la formación de una junta propia y leal al monarca y a las autoridades sustitutas de la vacancia real. ${ }^{76}$

71 Rodríguez, 1996; Portillo Valdés, 2002.

72 Ibarra, 2010

73 Palti, 2010.

74 Fernández Sebastián, 2010, 137.

75 San Francisco, 2014

76 Polastrelli, 2016. 
Fernández Sebastián remarcó que existen razones históricas particulares que explicarían la inclinación de las autoridades coloniales a tomar el término en su acepción más radical: independencia adquirió connotaciones bélicas y revolucionarias a partir de la guerra desatada contra Napoleón, situación que luego proyectaría los mismos temores y sentimientos sobre los americanos..$^{77} \mathrm{Y}$ aunque los intentos independentistas podían estar más bien ligados a la inquietud reinante en las autoridades, lo cierto es que el último tramo del siglo XVIII aportaba un ejemplo en el cual la posibilidad se había transformado en realidad: las colonias angloamericanas. Norteamérica no solo ofrecía una experiencia exitosa de ruptura con la metrópoli sino también un modelo alternativo de gobierno, la república. Si bien en la monarquía era frecuente la utilización del vocablo «república» para referir especialmente a las ciudades y cabildos, resulta indudable que en este contexto su uso mostraba cierto carácter de confrontación al gobierno monárquico porque atentaba contra sus principios constitutivos. ${ }^{78} \mathrm{~A}$ su vez, aunque el vocablo independencia en el sentido de ruptura existía antes, su significado político sufrió una fuerte torsión semántica con los acontecimientos de la revolución norteamericana, reactualizada por los propios sucesos de la Península. ${ }^{79}$ En ese contexto tan cambiante, Elías Palti señala una paradoja que plantea el interrogante por aquello que se concibe como el sujeto de la independencia: ¿eran las colonias americanas en su conjunto o eran las jurisdicciones que conformaban el Río de la Plata? ${ }^{80}$ En todos los casos aquí estudiados se advierte que la unidad territorial no aparece definida con claridad en ninguno de ellos.

Por otro lado, las demoras y las interrupciones que sufrieron las causas judiciales obedecieron a los conflictos y a las tensiones existentes entre las autoridades, que aprovecharon la situación de extrema fragilidad provocada por la vacancia real para medir sus fuerzas en las disputas por el reparto del poder. ${ }^{81}$ Estas rivalidades fueron utilizadas, según las diferentes coyunturas, a favor de los distintos actores involucrados en los diversos procesos. Las constantes intervenciones del gobernador de Montevideo Elío, el papel aparentemente pasivo de la Audiencia de Buenos Aires en las disputas y el punto de quiebre que marcó la llegada del virrey Cisneros en la criminalización

77 Fernández Sebastián, 2013.

78 Entin, 2013; Di Meglio, 2008, 145-158.

79 Fernández Sebastián, 2013.

80 Palti, 2010.

81 Polastrelli, 2016. 
y la condena de las alternativas políticas esgrimidas fueron factores que afectaron el desarrollo de los juicios.

Como se observó en este trabajo, Cisneros se esmeró en concluir las causas abiertas, pero también realizó activas gestiones para acabar con el clima conspirativo que reinaba en el virreinato, y particularmente en su capital. Dichas gestiones se materializaron en la creación de una Comisión de Vigilancia el 25 de noviembre de 1809 a cargo del fiscal del crimen de la Audiencia. La comisión debía perseguir, sin distinción de fueros, a quienes promoviesen «las detestables máximas del partido francés» y a cualquier «otro sistema contrario a la conservación de estos dominios en unión y dependencia de la metrópoli». ${ }^{82} \mathrm{El}$ temor frente a los intentos conspirativos durante estos años no fue exclusivo de las autoridades coloniales rioplatenses. Prácticamente en todos los territorios de la América española tuvieron lugar diversos episodios como resultado de la efervescencia política que caracterizó la coyuntura, y que pusieron en alerta a los representantes de la Corona. Similares también fueron las medidas ensayadas para contrarrestar dichos episodios. Los trabajos de Antonio Ibarra y Marco Antonio Landavazo sobre las Juntas de Seguridad y Buen Orden establecidas en Nueva España constituyen una muestra de ello. ${ }^{83}$

Las percepciones y representaciones que las autoridades españolas tuvieron sobre la independencia $-\mathrm{O}$ los «lenguajes políticos de la represión», en palabras de Rossana Barragán- concentraron las acusaciones y contribuyeron a definir discursivamente dos bandos enfrentados que, en la coyuntura incierta de 1806/08-1810, eran bastante más heterogéneos puesto que abarcaban una multiplicidad de aspiraciones. ${ }^{84}$ Queda entonces abordar cuáles fueron las significaciones que los implicados en los procesos judiciales analizados construyeron en torno a la «independencia». En sus defensas, los acusados sostuvieron su inocencia en la negación de cualquier tipo de participación en «planes independentistas» o, incluso, en el reconocimiento de la existencia de dichos proyectos, pero despojándolos del matiz negativo que los enlazaba, por ejemplo, a «revolución» o «subversión». En este último caso, quienes patrocinaron la ruptura total de los vínculos con la metrópoli, consideraron su viabilidad a partir de la asistencia de Inglaterra o Portugal, es decir, por medio de un protectorado o de una regencia. La figura

82 «Circular comunicando la creación del juzgado de vigilancia. Buenos Aires, 25 de noviembre de 1809», Biblioteca de Mayo, 1960, XVIII, 15965.

83 Ibarra, 2002; 2003; Landavazo, 2015.

84 Barragán, 2008, 168-170. 
de Rodríguez Peña es ilustrativa al respecto, ya que sus proyectos variaron de uno a otra. Ninguno de los alineamientos internos en el Río de la Plata puede comprenderse sin contemplar el papel de Gran Bretaña — con los vaivenes de sus sucesivos gobiernos respecto a qué estrategia asumir frente a las colonias hispanas - y el rol de Portugal, con su tradicional vocación expansionista sobre las posesiones españolas en el sur del continente..$^{85}$

Finalmente, la dilación en las causas posibilita percibir la reconfiguración que adoptaron las acusaciones a partir de los cambios políticos que se fueron efectuando. El «delito de independencia», tal como había sido caracterizado por las autoridades coloniales españolas, redefinió su valencia acusatoria a partir de la Revolución. Aunque el nuevo gobierno instalado en 1810 en Buenos Aires mantuvo su fidelidad al rey cautivo, rechazó a las autoridades que en la Península intentaban gobernar en su nombre y comenzó a dar muestras de una tenaz autonomía. En ese contexto, otros fueron los dilemas que inquietaron a la nueva elite dirigente a la hora de definir «enemigos». El delito de alta traición ya no le fue imputado a los sospechados de liderar planes independentistas sino a los que conspiraron contra la causa de la revolución. Así, si los delitos expuestos en los juicios analizados en este trabajo para la coyuntura de la crisis virreinal y monárquica fueron reputados como crímenes de lesa majestad, las acusaciones realizadas a partir de 1810 contra aquellos considerados «contrarrevolucionarios» se caratularon como de delitos de lesa patria ${ }^{86}$ La torsión semántica de la acusación exhibe las mutaciones producidas en el orden político y, fundamentalmente, en el principio de legitimidad que lo sustentaba: el máximo valor que lesionaban quienes fueron acusados de cometer delitos políticos ya no era Dios (como garante del orden sagrado e indisponible de las monarquías de Antiguo Régimen) sino la patria ${ }^{87}$ Pero evidencia también la persistencia de los gobiernos revolucionarios por mantener la unidad — sin divisiones - del cuerpo que surgía de la ruptura del orden colonial.

Recibido el 14 de agosto de 2017 Segunda versión el 6 de marzo de 2018

Aceptado el 23 de marzo de 2018

85 Actualmente una línea de investigación reconoce a Brasil y a Hispanoamérica como parte de un mismo espacio político, el mundo iberoamericano. Véase Pimenta, 2011. Sobre las posturas dentro del gabinete inglés respecto de las colonias españolas, véase Gallo, 1994.

86 Polastrelli, 2012.

87 Barriera, 2018. Citamos también el estudio sobre la justicia revolucionaria de Bragoni, 2008. 


\section{Referencias bibliográficas}

Annino, Antonio, «Imperio, constitución y diversidad en la América hispánica», Historia Mexicana, 58, México, 2008, 179-227.

Ávila, Alfredo, «¿Cómo ser infidente sin serlo? El discurso de la independencia en 1809», en Castro, F. y Terrazas, M. (eds.), Disidencia y disidentes en la historia de México, México, UNAM, 2003, 139-168.

Barragán, Rossana, «Los discursos políticos de la represión: una comparación entre 1781 y 1809», Secuencia, Número conmemorativo, México, 2008, 163-198.

Barriera, Darío G., «Orden jurídico y forma política en un concepto desplazado: crimen (siglos XVII-XX)», en Bonaudo, M.; Reguera, A. y Zeberio, B. (coords.), Las escalas de la historia comparada. Tomo I: Dinámicas sociales, poderes políticos y sistemas jurídico, Buenos Aires, Miño y Dávila, 2008, 229-246.

Barriera, Darío G., «La tierra nueva es algo libre y vidriosa. El delito de "traición a la Corona Real": lealtades, tiranía, delito y pecado en la jurisdicción de la Real Audiencia de Charcas (1580-81)», Ley, Razón y Justicia, 11, Neuquén, 2010, 281-305.

Barriera, Darío G., «La historia del poder político rioplatense durante el "periodo colonial": interpelaciones desde el prisma de la historia de la Justicia», en Peire, J.; Amadori, A. y Chaile, T. (eds.), Historiografías político-culturales rioplatenses. Itinerarios, enfoques y perspectivas recientes sobre el período colonial y la independencia, Sevilla, Thémata, 2018, 23-56.

Biblioteca de Mayo. Colección de obras y documentos para la historia argentina, Buenos Aires, Senado de la Nación, 1960.

Brading, David A., Orbe indiano. De la monarquía católica a la república criolla, 1492-1867, México, Fondo de Cultura Económica, 1991.

Bragoni, Beatriz, «La justice révolutionnaire en Amérique du Sud pendant les guerres d'indépendance. Le procès des frères Carrera (1818)», Annales. Histoire, Sciences Sociales, 5, París, 2008, 949-976.

Breña, Roberto (ed.), El umbral de las revoluciones hispánicas: el bienio 18081810, México, El Colegio de México / Centro de Estudios Constitucionales, 2010.

Buriano, Ana y Grafenstein, Johanna von, «Introducción», Secuencia, Número conmemorativo, México, 2008, 5-20.

Chiaramonte, José Carlos, Ciudades, provincias, Estados: Orígenes de la Nación Argentina (1800-1846), Buenos Aires, Ariel, 1997.

Chust, Manuel (coord.), 1808. La eclosión juntera en el mundo hispano, México, Fondo de Cultura Económica / El Colegio de México, 2007a.

Chust, Manuel, «Un bienio trascendental: 1808-1810», en Chust, M. (coord.), 1808. La eclosión juntera en el mundo hispano, México, FCE / ECM, 2007b, 11-50. 
Di Meglio, Gabriel, «Patria»y «República», en Goldman, N. (ed.), Lenguaje y Revolución. Conceptos políticos clave en el Río de la Plata, 1780-1850, Buenos Aires, Prometeo, 2008, 115-129 y 145-158.

Entin, Gabriel, «El patriotismo americano en el siglo XVIII. Ambigüedades de un discurso político hispánico», en Hébrard, V. y Verdo, G. (eds.), Las independencias hispanoamericanas. Un objeto de historia, Madrid, Casa de Velázquez, 2013, 19-34.

Fernández Sebastián, Javier (dir.), Diccionario político y social del mundo iberoamericano, Madrid, Centro de Estudios Políticos y Constitucionales, 2009 y 2014, 11 vols. en 2 tomos.

Fernández Sebastián, Javier, «Comentario al texto de Ana Carolina Ibarra», en Palti, E. (coord.), Mito y realidad de la «cultura política latinoamericana». Debates en IberoIdeas, Buenos Aires, Prometeo, 2010, 135-140.

Fernández Sebastián, Javier, «La independencia de España y otras independencias. La transformación radical de un concepto en la crisis del mundo hispano», en Ávila, A.; Dym, J. y Pani, E. (coords.), Las declaraciones de independencia. Los textos fundamentales de las independencias americanas, México, El Colegio de México / UNAM, 2013, 41-80.

Frega, Ana, «La junta de Montevideo de 1808», en Chust, M. (coord.), 1808. La eclosión juntera en el mundo hispano, México, FCE / ECM, 2007, 242-268.

Gallo, Klaus, De la invasión al reconocimiento. Gran Bretaña y el Río de la Plata. 1806-1826, Buenos Aires, AZ Editora, 1994.

Goldman, Noemí (ed.), Lenguaje y revolución. Conceptos políticos clave en el Río de la Plata, 1780-1850, Buenos Aires, Prometeo, 2008.

Goldman, Noemí, ;El pueblo quiere saber de qué se trata! Historia oculta de la Revolución de Mayo, Buenos Aires, Sudamericana, 2009.

Goldman, Noemí, «Soberanía en Iberoamérica. Dimensiones y dilemas de un concepto fundamental, 1780-1870», en Fernández Sebastián, J. (dir.), Diccionario político y social del mundo iberoamericano, Madrid, Centro de Estudios Políticos y Constitucionales / Universidad del País Vasco, 2014, tomo II, vol. $10,15-41$.

Goldman, Noemí, Mariano Moreno. De reformista a insurgente, Buenos Aires, Edhasa, 2016.

Guerra, François-Xavier, Modernidad e Independencia. Ensayos sobre las revoluciones hispánicas, Madrid, MAPFRE, 1992.

Halperin Donghi, Tulio, Revolución y guerra. Formación de una elite dirigente en la Argentina criolla, Buenos Aires, Siglo XXI, 2005.

Ibarra, Ana Carolina, «Autonomía e independencia en la crisis del orden virreinal», en Palti, E. (coord.), Mito y realidad de la «cultura política latinoamericana», Buenos Aires, Prometeo, 2010, 119-133.

Ibarra, Antonio, «Crímenes y castigos políticos en la Nueva España borbónica: patrones de obediencia y disidencia política, 1809-1816», en Terán, M. y 
Serrano Ortega, J. A. (eds.), Las guerras de independencia en la América española, Zamora (Mich.), El Colegio de Michoacán / Universidad Michoacana de San Nicolás de Hidalgo / INAH, 2002, 255-272.

Ibarra, Antonio, «La persecución institucional de la disidencia novohispana: patrones de inculpación y temores políticos de una época», en Castro Gutiérrez, F. y Terrazas, M. (coords.), Disidencia y disidentes en la historia de México, México, UNAM / Instituto de Investigaciones Históricas, 2003, 117-138.

Irurozqui, Marta, «Del Acta de los Doctores al Plan de Gobierno. Las juntas en la Audiencia de Charcas (1808-1810)», en Chust, M. (coord.), 1808. La eclosión juntera en el mundo hispano, México, FCE / ECM, 2007, 192-226.

Irurozqui, Marta, «Soberanía y castigo en Charcas. La represión militar y judicial de las juntas de La Plata y La Paz, 1808-1810», Revista Complutense de Historia de América, 37, Madrid, 2011, 49-72.

Landavazo, Marco Antonio, «El fantasma de la infidencia. Expresiones antimonárquicas en Nueva España en vísperas de la independencia», Tzintzun. Revista de Estudios Históricos, 62, Morelia, 2015, 44-68.

Mayo documental, Buenos Aires, Universidad de Buenos Aires, Kraft, 1962.

Ortelli, Sara, «Enemigos internos y súbditos desleales. La infidencia en Nueva Vizcaya en tiempos de los Borbones», Anuario de Estudios Americanos, LVI, 2, Sevilla, 2004, 467-489.

Ortelli, Sara y Barral, María Elena, «Una sociedad de frontera en vísperas de la independencia: el Río de la Plata en 1808», Secuencia, Número conmemorativo, México, 2008, 243-264.

Palti, Elías, «Perspectivas plurales, problemáticas comunes: Un comentario al número de Historia Mexicana "1808: Una coyuntura germinal”», Historia Mexicana, 232, México, 2009, 1447-1476.

Palti, Elías, «Respuesta al texto de Ana Carolina Ibarra», en Palti, E. (coord.), Mito y realidad de la «cultura política latinoamericana», Buenos Aires, Prometeo, 2010, 141-142.

Pasino, Alejandra, «Independencia. Argentina/Río de la Plata», en Fernández Sebastián, J. (dir.), Diccionario político y social del mundo iberoamericano, Madrid, Centro de Estudios Políticos y Constitucionales, 2014, tomo II, vol. 4, 33-48.

Peralta Ruiz, Víctor, «Las juntas de gobierno hispanoamericanas (1808-1814). Reflexiones en el contexto del Bicentenario de las Independencias», Historia y Cultura, 26, Lima, 2013, 9-40.

Pimenta, João Paulo, Estado y Nación hacia el final de los imperios ibéricos. Río de la Plata y Brasil, 1808-1828, Buenos Aires, Sudamericana, 2011.

Piqueras, José A. (coord.), «1808: una coyuntura germinal», Historia Mexicana, número monográfico, 229, México, 2008, 5-486.

Polastrelli, Irina, «La disidencia política y sus condenas. Los juicios a Martín de Alzaga, 1809-1812», en Tejerina, M. (comp.), Definir al Otro. El Río de la 
Plata en tiempos de cambio (1775-1820), Bahía Blanca, EDIUNS, 2012, 109-137.

Polastrelli, Irina, «La disidencia ante la justicia. Reacciones frente a la crisis de la monarquía en el Río de la Plata, 1808-1810», Secuencia, 96, México, 2016, 45-72.

Portillo Valdés, José María, «Crisis de la monarquía, 1808-1812», en Fernández Albadalejo, P. (ed.), Los Borbones. Dinastía y memoria de nación en la España del siglo XVIII, Madrid, Marcial Pons / Casa de Velázquez, 2002, 597-626.

Portillo Valdés, José María, «Entre la monarquía y la nación: cortes y constitución en el espacio imperial español», en Portillo Valdés, J. M.; Veiga Alonso, X. R. y Baz Vicente, M. J. (coords.), A Guerra da independencia e o primeiro liberalismo español, Santiago de Compostela, Universidade de Santiago de Compostela, 2009, 129-156.

Rodríguez O., Jaime E., La independencia de la América española, México, Fondo de Cultura Económica, 1996.

Rosanvallon, Pierre, «Para una historia conceptual de lo político (nota de trabajo)», Prismas. Revista de historia intelectual, 6, Buenos Aires, 2002, 123-136.

San Francisco, Alejandro, «Independencia: Un concepto político y social en revolución (1770-1870», en Fernández Sebastián, J. (dir.), Diccionario político y social del mundo iberoamericano, Madrid, Centro de Estudios Políticos y Constitucionales, 2014, tomo II, vol. 4, 15-32.

Sbriccoli, Mario, Crimen laesae maiestatis. Il problema del reato politico alle soglie della scienza penalistica moderna, Milano, Giuffrè, 1974.

Souto, Nora y Wasserman, Fabio, «Nación», en Goldman, N. (ed.), Lenguaje y revolución. Conceptos políticos clave en el Río de la Plata, 1780-1850, Buenos Aires, Prometeo, 2008, 83-98.

Ternavasio, Marcela, «De la crisis del poder virreinal a la crisis del poder monárquico. Buenos Aires, 1806-1810», en Breña, R. (ed.), En el umbral de las revoluciones hispánicas: el bienio 1808-1810, México / Madrid, El Colegio de México / Centro de Estudios Políticos y Constitucionales, 2010a, 265-298.

Ternavasio, Marcela, «Política y cultura política ante la crisis del orden colonial», Boletín del Instituto de Historia Argentina y Americana Dr. Emilio Ravignani, 33, Buenos Aires, 2010b, 39-53.

Ternavasio, Marcela, Candidata a la Corona: La infanta Carlota Joaquina en el laberinto de las revoluciones hispanoamericanas, Buenos Aires, Siglo XXI Editores, 2015.

Wasserman, Fabio, Juan José Castelli. De súbdito de la corona a líder revolucionario, Buenos Aires, Edhasa, 2011. 